\title{
Bladder pressure and kidney function in children with myelomeningocoele: review article
}

\author{
R L Vereecken
}

Department of Urology, St-Pieter University Hospital, Brusselsestraat 69, B-3000 Leuven, Belgium.

Therapy of children with myelomeningocoele should achieve a double goal: on the one hand, obtain continence and, on the other hand, preserve kidney function without complications. The first goal is a social and psychological one, the latter is a vital one.

Key words: myelingocoeles; urinary bladder hyperpressure; neuropathic incontinence.

\section{Bladder function}

Capacity and residual urine

In order to obtain continence a sufficient bladder capacity is necessary. In the literature the bladder capacity values in normal children vary widely according to different authors. The values of Muellner, ${ }^{1}$ Starfield $^{2}$ and Berger et $a l^{3}$ are rather similar, while the capacities mentioned by Van Gool et al $^{4}$ and Esperanca ${ }^{5}$ are much lower and those of Hallman ${ }^{6}$ and much higher than the values of previous authors (Fig 1). The reasons underlying these discrepancies are numerous. The maximum capacity determined during the urodynamic session is different when the patient is asked to suppress the micturition act as long as possible and when he is allowed to void at the time of the first uncomfortable sensation. The psychological stress of a child who wishes to finish the examination as soon as possible is different from that of a quiet, eventually mentally retarded child, or a child drinking milk or under superficial anaesthesia. After water load the capacity is smaller than with physiological filling and the bladder filling rate can therefore also play a role; girls seem to have larger capacities than boys. ${ }^{5}$

For a long time a residual urine of less than one-sixth of the bladder capacity has been considered to be the golden standard in urological bladder disorders. However, this theoretical value must in practice be adapted to the particular situation. For example, if there is infected urine, these residues can be detrimental to the bladder and the kidney, while larger residual volumes are acceptable if sterile.

Post voiding residual urine expressed as a percentage of bladder capacity is related to the cystometric pattern: in hypertonic dyssynergic bladders the post voiding residual urine is $65 \%$ against $9 \%$ in synergic bladders, while in hypotonic bladders the postvoiding residue is about $25 \%$ in dyssynergic hypertonic as well as in synergic bladders. ${ }^{7}$ High residual urine is important in different

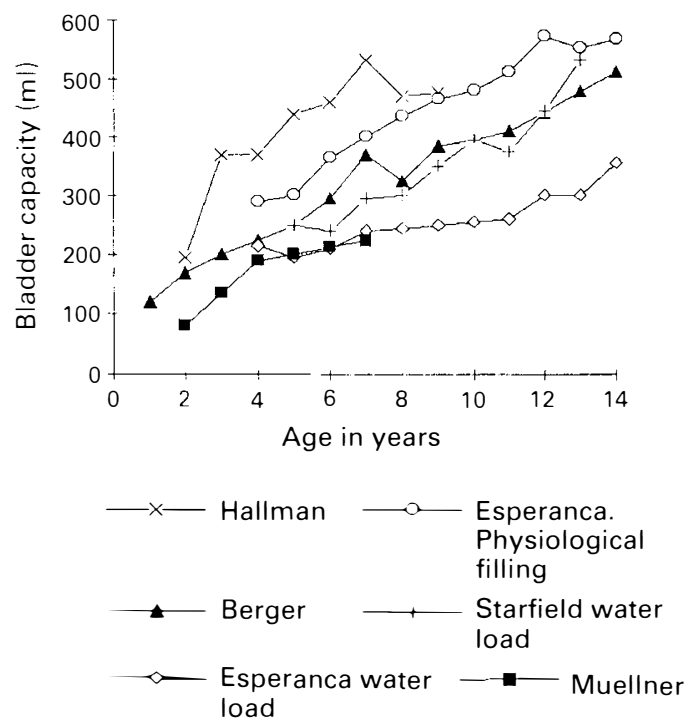

Figure 1 Bladder capacities in children (different authors). 
aspects: (1) it diminishes the functional capacity (total capacity minus residual volume), thereby increasing the frequency of micturition and the incontinence; (2) residual urine is often a result of incomplete bladder contraction at higher filling volumes. As soon as the small voided volume is replaced by diuresis, a new contraction (with leakage) occurs. In a 24 hour ambulatory measurement in a 12 year old spina bifida child, we calculated a total duration of 7.45 hours, during which the bladder pressure exceeded $40 \mathrm{~cm}$ of water. This total time was reduced to 1.05 hours simply by 5 intermittent catheterisations of a mean of $120 \mathrm{ml}$ residual urine; and (3) regular catheterisation can improve continence as well as urinary infection, and is more acceptable to parents and children (who usually have no pain sensation). Simultaneous administration of oxybutinin gives an increased bladder capacity and low pressure.

\section{Incontinence}

Incontinence is always the result of an imbalance between intravesical pressure and urethral resistance. This relation can only be evaluated by urodynamic examinations. It should be stressed that the result of a urodynamic investigation may be different from that which would be expected from the anatomical spine defect level, ${ }^{8}$ but also from the clinical neurological finding such as a bulbocavernosus reflex, anal reflex, level of skin sensation and the control of the striated muscles in the lower limbs. Only urodynamic examination can detect candidates at risk of deterioration of bladder function. Although no evolution is usually expected before the age of 2 or 3 years, this detection is already necessary in neonates especially in the presence of vesicoureteral reflux.

\section{Bladder hyperactivity}

The hyperactive bladder can be either hyperreflexive or of low compliance (Fig 2). In the first case, the baseline remains at low pressure but superimposed uninhibited contractions at variable filling volumes and pressure amplitude occur. This hyperreflexive bladder type is rather rare in its pure form in myelomingocoele patients. In those with low compliance, the pressure volume curves show a slope in which the angle is a function of the distensibility of the bladder wall. Low compliance can be due to muscle hypertrophy, denervation, fibrosis or chronic infection. According to Bauer ${ }^{9}$ et al, of the initial $50 \%$ of myelodysplastic newborns with an upper motor neuron type of neuropathic bladder dysfunction, $30 \%$ remain after puberty suggesting a progressive lesion in some children.

Even the hypoactive bladder, which in fact is areflexive and can lead in some cases to complete retention, may mask a latent hyperreflexia. A bladder which is empty most of the time because of low urethral resistance, can show a hyperreflexive pattern as soon as the outlet resistance is increased, eg after implantation of an AMS 800 sphincter or by bladder neck suspension. Detrusor hypertonia can be misjudged if the urethral resistance is so low that leakage of urine is already occurring in the presence of low bladder pressures, or when unchanging urethral resistances become equilibrated by an autonomous increasing intravesical presssure.

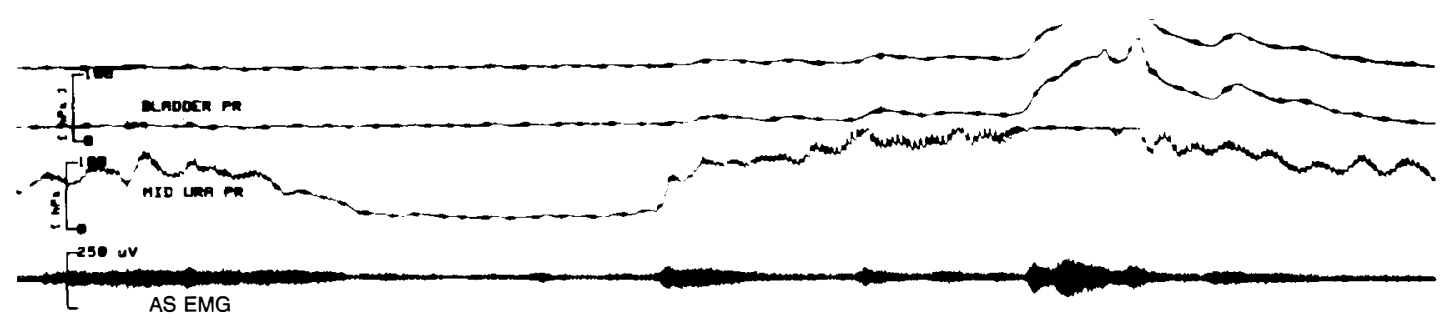

Figure 2 Dyssynergia between anal sphincter (AS EMG) and detrusor pressure (upper curve) during an uninhibited bladder contraction. Note also the previous abnormal decrease of activity (accompanied with mid urethral pressure fall). 
Woodside $^{10,11}$ described a simple urodynamic test which permits prediction of the final outcome of urethral resistance augmentation either by surgery or by artificial sphincters. He repeats the cystometry with a balloon catheter occluding the bladder neck so that no urine can escape; often low compliance bladders are then converted to high pressure bladders.

\section{Urethral hyperactivity}

In order to assure continence the urethral resistance must be more than $60 \mathrm{~cm} \mathrm{H}_{2} \mathrm{O}$ even in areflexive bladders: in this case intermittent catheterisation is the ideal solution and the patients are dry between successive catheterisations. In myelodysplasia a closure pressure of more than $60 \mathrm{~cm}$ $\mathrm{H}_{2} \mathrm{O}$ occurs in only $30 \%$ of patients; this closure pressure usually decreases with time.

A hyperactive urethra can be caused by involvement of either smooth muscle or of the striated perineal musculature. Normally the urethra is closed except during voiding. Changing position from supine to sitting can cause a sympathetic dyssynergia even with inactive somatic EMG curves. According to Mundy et $a l^{12}$ the bladder neck either competent or incompetent is never obstructive and is always incompetent in acontractile bladders at their usual bladder volumes.

Upper motor neuron lesion dyssynergia is a dynamic phenomenon which increases with age. Striated urethral muscle spasms can result with time in retractile fibrosis. Dyssynergia can be seen on permictional urethrography as a constricted area (Fig 4). During rehabilitation voiding manoeuvres (Credé or Valsalva) increased activity in the perineum can be observed; this activity counteracts the effect of these procedures.

Different types of external sphincter dyssynergia have been described: ${ }^{3}$ a full contraction of the sphincter throughout the increase in bladder pressure (Fig 2), a small contraction only at the beginning of the increase in bladder pressure, a waxing and waning pattern corresponding to changes in the intravesical pressure, and a sphincter hyperactivity with detrusor areflexia as seen in patients after muscarin blockade. ${ }^{14}$ It is difficult to quantify the effect of electromyo- graphic activity on outflow resistance. By applying the technique of electromyographic differentiation ${ }^{15}$ we found in most patients a correlation of more than 0.8 between urethral pressure and electromyographic activity (Fig 3). Therefore dyssynergia may indeed be a cause for difficult voiding and thus a cause of bladder hyperpressure.

Outflow obstruction in the form of detrusor sphincter dyssynergia can also lead to impaired urinary tract drainage in a significant number of babies. It also allows identification in the newborn who are at risk from such a complication. In older children voiding dysfunction from external sphincter hyperactivity can be reflected in the simple radiographic sign of prostatic reflux, although this reflux can also occur without any sphincter activity (Fig 4). The non relaxing type of urethral hyperactivity often occurs in lower motor neuron lesions where dysuria is expressed by a static continuous urethral pressure together with an areflexive bladder.

In the literature there is disagreement about the percentage of different types of bladder-urethra behaviour. Hyperactive sphincters usually occur as frequently as areflexive sphincters. A hyperactive sphincter is associated with a hyperactive bladder in $34 \%$ of patients, whilst an areflexive sphincter occurs together with an areflexive bladder in $38 \%$ of patients. These figures by Van Gool et al ${ }^{4}$ are confirmed by Webster et $a l^{16}$, Light et $a l^{17}$ and Wijndale. ${ }^{18}$ The majority of patients without hyperactivity have a lesion located higher up in the spinal cord according to Naglo, ${ }^{19}$ but we could not confirm this finding. ${ }^{8}$

Since urethral hyperactivity provokes outflow obstruction, internal urethrotomy can be helpful. ${ }^{20}$ The distant sphincter mechanism is nearly always dynamically obstructive in children with contractile bladders whereas in children with acontractile bladders some degree of static distal sphincter contraction and sphincter weakness incontinence exists simultaneously.

\section{Evolution}

Bladder function may change with time. We have already mentioned a conversion of 

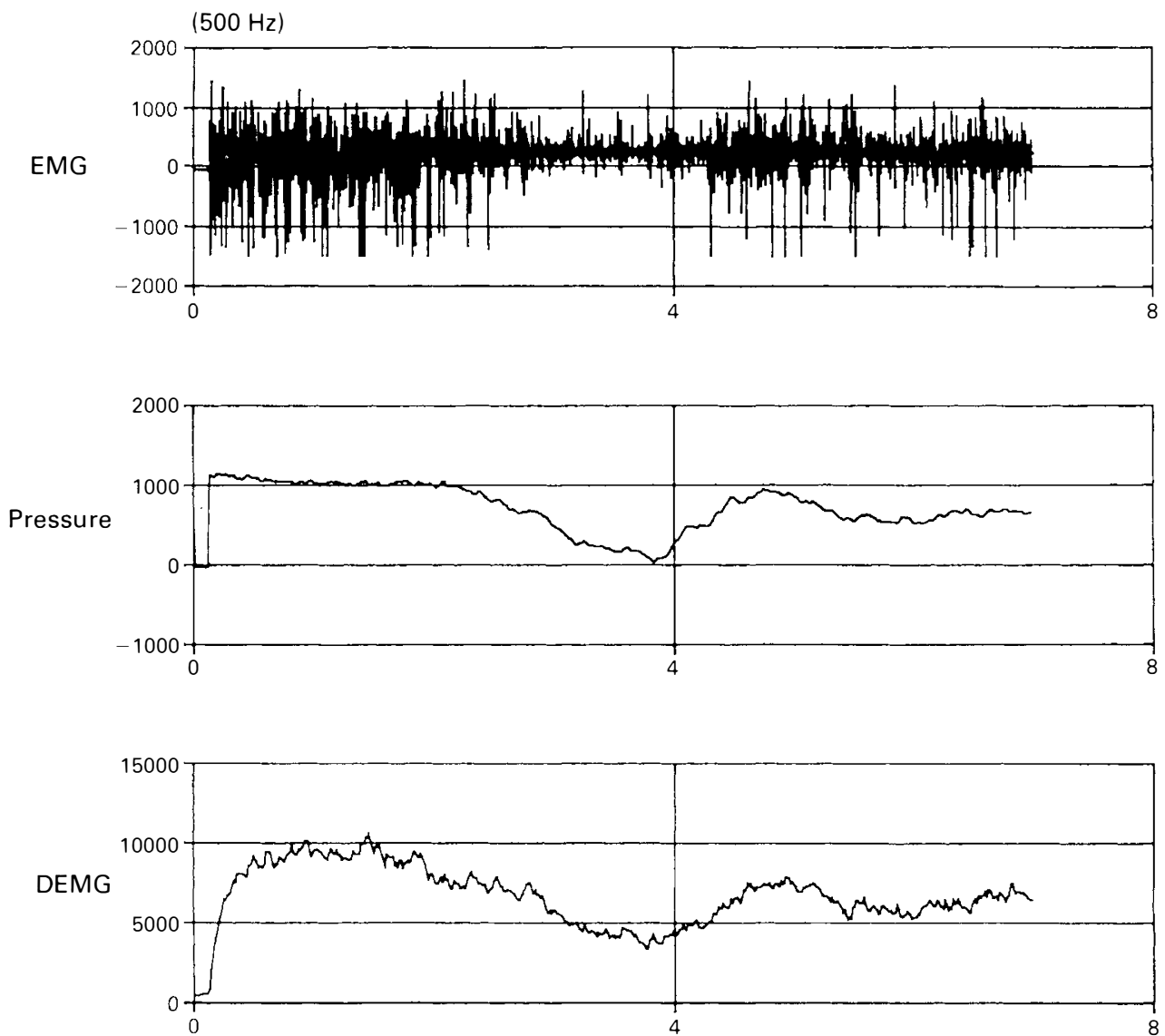

Figure 3 Electromyographic activity in the periurethral striated muscle (EMG in $\mu \mathrm{V}$ ), urethral pressure (pressure $1000=50 \mathrm{cmH}_{2} \mathrm{O}$ ) and Differential of EMG (DEMG) during a 6 second period. Note the degree of correlation $(0.87)$.

areflexia to hyperreflexia after the implantation of an artificial sphincter, probably because the bladder wall distension increases afferent input thereby stimulating detrusor activity. The opposite situation may also occur: eg in patients undergoing sphincterotomy a hyperreflexive bladder can convert into a nearly areflexive state.

Bladder function deterioration can be ascribed to 3 different factors: (1) evolution of the central neural lesion: resorption of haematoma, fibrosis, surgical interventions, tethered cord and other evolution lesions; (2) changes in the peripheral neural system. Sundin et $a l^{21}$ demonstrated that in the denervated bladder a gradual increase of the orthopathic system influence occurred because of the spread of the orthopathic nervous fibres into mucles previously innervated by the parasympathetic system. Since the orthosympathic system augments the tone of the bladder, increased bladder pressures and low compliance occur. The beneficial effect of alpha-adrenergic blocking agents confirms this theory; and (3) fibrosis and infection provoke an increase of collagenous tissue between the muscle bundles thus decreasing the compliance of the detrusor and promoting incontinence.

\section{Kidney function}

The main reason for the follow up of patients with myelingocoele is the preservation of kidney function. Indeed, vesicoureteral reflux, infection, and hydronephrosis 


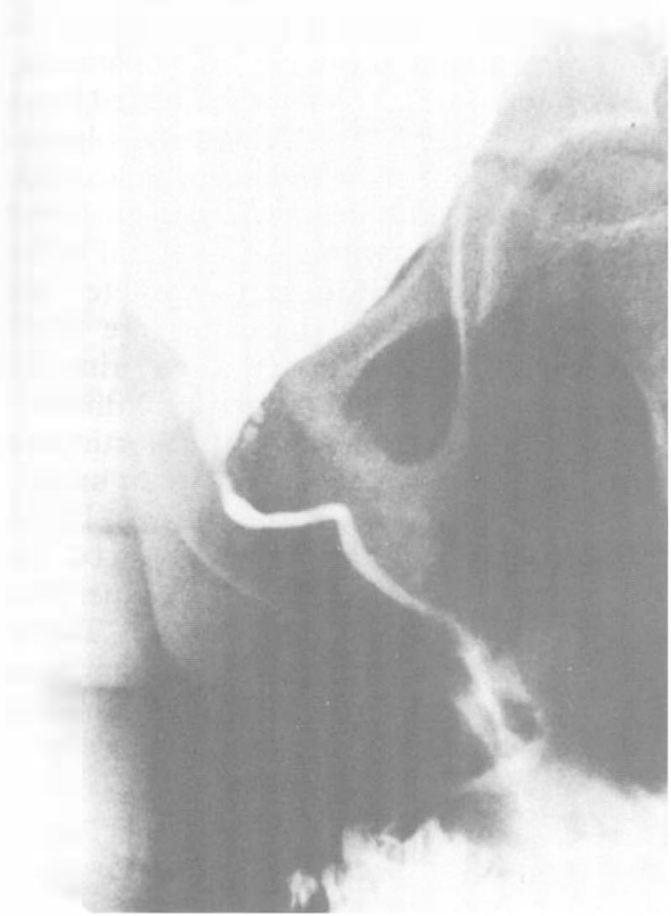

Figure 4 Permictional cystourethrography in a spina bifida boy. Note the narrow region at the external sphincter and the intraprostatic reflux of contrast medium.

are often found at adult age and cause renal insufficiency. This deterioration of kidney function is usually related to poor bladder function. The combination of urodynamic testing with nuclear renography is useful and practical.

\section{Influence of bladder pressure on the proximal urinary tract}

Several authors draw attention to the sinister implications of high bladder pressures occurring several times a day or of a chronic high pressure retention. George et $a l^{22}$ described the syndrome of high pressure chronic retention in men with obstructive uropathy: they had a late onset enuresis, a tense painless palpable bladder, hypertension and renal impairment associated with bilateral hydroureteronephrosis. McGuire et $a l^{23}$ showed in a group of 42 myelodysplastic patients with a follow up of 7 years that in patients with an intravesical pressure of more than $40 \mathrm{~cm} \mathrm{H}_{2} \mathrm{O}$ at the moment of urethral leakage, vesicoureteral reflux is seen in $68 \%$ of the cases and ureteral dilatation on excretory urography in $81 \%$. Steinhardt et $a l^{24}$ demonstrated by renal scanning in meningocoele patients a consistent and significant decrease in glomerular filtration rate at high bladder pressures. In another 6 patients Zwiers et al ${ }^{25}$ demonstrated by radionuclide renography an obstructed pattern when the bladder was filled up to the volume that during previous urodynamic testing resulted in an intravesical pressure of $40 \mathrm{~cm} \mathrm{H}_{2} \mathrm{O}$. The same relationship between pressure and upper urinary tract function exists in patients with spinal cord injury, multiple sclerosis, and vesical decentralisation syndromes.

In a prospective study of 250 myelodysplasia patients McLorie et al ${ }^{26}$ demonstrated that significant determinants of vesicoureteral reflux include a change in bladder shape, the presence of uninhibited contractions and the presence of dyssynergia. Renal deterioration was noted and predicted by the presence of vesicoureteral reflux, a high urethral pressure profile and dyssynergia. In another study on myelodysplastic patients McGuire ${ }^{27}$ showed that the clinical presence of upper urinary tract deterioration may manifest itself after many years of normality and often as late as the mid teenage years; anticholinergic medication, frequently in conjunction with intermittent catheterisation, is of the utmost importance in the prevention of kidney function deterioration in patients presenting detrusor hypertonia. Jones et al ${ }^{28}$ demonstrated that pelvic pressures are markedly elevated when the flow in the upper urinary tract was increased by oral waterload or furosemide and then accurately reflect any change in intravesical pressure. Under these conditions the pelvic pressures frequently exceeds $40 \mathrm{~cm} \mathrm{H}_{2} \mathrm{O}$, which is the safety limit described by McGuire et al. ${ }^{27}$

\section{Bladder pressure related to changing circumstances}

It should be stressed that pressure values obtained during a urodynamic session are not necessarily comparable to values exist- 
ing throughout the day when the bladder is filled by natural kidney secretion. Styles et $a l^{29,30}$ found a 2 times higher effective cystometric capacity during standard cystometry than during long term monitoring, while detrusor instability was greater. High filling pressure commonly observed in men with chronic retention investigated by means of a standard cystometrogram are often absent during long term monitoring; they are probably due to the unphysiological filling rates and to the larger volumes of infused fluid. Therefore, the normal upper urinary tract observed in $30 \%$ of the patients showing high bladder pressures in the cystometrogram could signify that the high pressures are artificial. Nevertheless, Styles ${ }^{29,30}$ clearly demonstrated by long term bladder pressure monitoring that a significant correlation exists between frequently occurring uninhibited detrusor contractions, upper tract dilatation and impaired glomerular filtration rates; the amplitude of the unstable detrusor contractions was not directly related to the upper tract dilatation.

Another situation where measured bladder pressures do not reflect the real bladder status is in patients who have a vesicoureteral reflux. Woodside et al ${ }^{11}$ demonstrated that if the ureters with vesicoureteral reflux are occluded by a Fogarty catheter the measured intravesical pressures are much higher than those measured when urine can escape into the ureter and pelvis. Williams ${ }^{31}$ already considered reflux and diverticulum as a safety valve in children with low urinary tract obstructions, eg urethral valves. In this condition detrusor hypertonia can be neglected and this can result in operative failure after reconstructive surgery. Therefore reflux in the presence of significant detrusor hypertonia should be treated firstly by anticholinergic medication before performing a ureteroneocystostomy.

\section{References}

1 Muellner SR (1960) Development of urinary control in children. Some aspects of the cause and treatment of primary enuresis. JAMA 172: 1256-1261.

2 Starfield B (1967) Functional bladder capacity in enuretic and nonenuretic children. J Pediat 70: 777

3 Berger RM, Maizels M, Moran GC, Conway JJ, Firlit CF (1983) Bladder capacity (ounces) equals age (years) plus 2 predicts normal bladder capacity and aids in diagnosis of abnormal voiding patterns. J. Urol 129: 347-349.

4 Van Gool JD, Kuijtẹn RH, Donckerwolcke RA, Kramer PP (1982) Detrusor-sphincter dyssynergia in children with myelomeningocele: a prospective study. Z Kinderchir 37: 148

5 Esperanca M, Gerrard JW (1969) Nocturnal enuresis: studies in bladder function in normal children and enuretics. Canad Med Ass J 101: 324-327.

6 Hallman N (1950) On the ability of enuretic children to hold urine. Acta Paediat 39: 87

7 Blaivas JG, Labib KL, Bauer SB, Retik AB (1977) Changing concepts in the urodynamic evaluation of children. J Urol 117: 778-782.

8 Vereecken RL, Verpoorten C, Lissens M (1990) Etude urodynamique, radiologique et clinique chez des enfants avec spina bifida. Acta Urol Belg 58: 79-86.

9 Bauer SB, Hallet M, Khoshbin S, Lebowitz RL, Winston KR (1984) Predictive value of urodynamic evaluation in newborns with myelodysplasia. JAMA 252: 650-652.

10 Woodside JR, Borden TA (1982) Determination of true intravesical filling pressure in patients with vesicoureteral reflux by Fogarty catheter occlusion of ureters. J Urol 127: 1149-1152.

11 Woodside JR, McGuire EJ (1982) Technique for detection of detrusor hypertonia in the presence of urethral sphincter incompetence. J Urol 127: 740-743.

12 Mundy AR, Shah PJR, Borzyskowski M, Saxton HM (1985) Sphincter behaviour in myelomeningocele. $\mathrm{Br}$ J Urol 57: 647-651.

13 Blaivas JG, Sinha JP, Zayed AAH, Labib KB (1981) Detrusor-external sphincter dyssynergia: a detailed electromyographic study. J Urol 125: 545-548.

14 O'Reilly PH, Brooman PJC, Farah NB, Mason GC (1986) High pressure chronic retention. Incidence, aetiology and sinister implications. J Urol 58: 644-646.

15 Van Leemputte M, Spaepen AJ, Willems EJ (1984) Quantification of EMG using a differentiation technique. In: Ducheyne P, Van der Perre G, Aubert E (eds). Biomaterials and Biomechanics. Elsevier, Amsterdam: 103-108.

16 Webster GD, El-Mahrouky A, Stone AR, Zakrzewski C (1986) The urological evaluation and management of patients with myelodysplasia. J Urol 58: 261-265.

17 Light JK, Faganel J, Roth DR, Dimitrijevic MR (1984) Meningomyelocele: a clinical, urodynamic and neurophysiological evaluation. J Urol 131: 717-721. 
18 Wijndaele JJ, de Sy WA (1985) Correlation between the findings of a clinical neurological examination and the urodynamic dysfunction in children with myelodyplasia. J Urol 133: 638-639.

19 Naglo AS, Nergardh A (1981) Diagnosis of detrusor hyperactivity in children with neurogenic bladder. Scand J Urol Nephrol 15: 91-96.

20 Rickwood AMK (1982) Use of internal urethrotomy to reserve upper renal tract dilatation in children with neurogenic bladder dysfunction. J Urol 54: 292-294.

21 Sundin T, Dahlstroem A (1973) The sympathetic innervation of the urinary bladder and urethra in the normal state and after parasympathetic denervation at the spinal root level. Scand J Urol Nephrol 7: 131-149.

22 George NJR, O'Reilly PH, Barnard RJ, Blacklock NJ (1983) High pressure chronic retention. Br Med J 286: $1780-1783$.

23 McGuire EJ, Woodside JR, Borden TA, Weiss RM (1981) Prognostic value of urodynamic testing in myelodysplastic patients. J Urol 126: 205-209.

24 Steinhardt GF, Goodgold HM, Samuels LD (1988) The effect of intravesical pressure on glomerular filtration rate in patients with myelomeningocele. J Urol 140: 1293-1295.

25 Zwiers W, Van Driel M, de Ruiter BJ, Beekhuis H, Piers BA (1987) Raionuclide renography to evaluate urodynamically expected upper tract obstruction in patients with meningomyelocele. J Urol 128: 845-846.

26 McLorie GA, Perez-Marero R, Csima A, Churchill BM (1988) Determinants of hydronephrosis and renal injury in patients with myelomeningocele. J Urol 140: 1289-1292.

27 McGuire EJ, Woodside JR, Borden TA (1983) Upper urinary tract deterioration in patients with myelodysplasia and detrusor hypertonia: a follow-up study. J Urol 129: 823-826.

28 Jones DA, Holden D, George NJR (1988) Mechanism of upper tract dilatation in patients with thick walled bladders, chronic retention of urine and associated hydroureteronephrosis. J Urol 140: 326-334.

29 Styles RA, Ramsden PD, Neal DE (1986) Chronic retention of urine. The relationship between upper tract dilatation and bladder pressure. Br J Urol 58: 647-651.

30 Styles RA, Neal DE, Ramsden PD (1986) Camparison of long-term monitoring and standard cystometry in chronic retention of urine. Br J Urol 58: 652

31 Williams DI (1958) Urology in childhood. Encyclopedia of Urology, XV. Springer Verlag, Berlin. 